Forthcoming in History and Philosophy of Logic (published online first: www.tandfonline.com/thpl).

\title{
The Structure and Extension of (Proto)type Concepts: Husserl's Correlationist Approach
}

\author{
Hamid Taieb
}

\begin{abstract}
This paper aims to reassess a notion in the works of the later Husserl that is both historically important and philosophically insightful, but remains understudied, namely, that of type. In opposition to a standard reading which treats Husserl's type presentations as pre-conceptual habits, this paper argues that these representations are a specific kind of concept. More precisely, it shows that Husserl's account of type presentations is akin to the contemporary prototype theory of concepts. This is historically important, since the predecessor of the prototype theory is usually said to be Wittgenstein. From a philosophical standpoint, the paper shows that Husserl has an innovative account of the connection between type concepts and their extension. Contrary to the standard view of extensions as sets and thus sharp entities, Husserl develops a correlationalist theory of concepts, according to which, for the specific characteristics in the structure of a concept, there are corresponding characteristics in the arrangement of its members, and vice versa. According to this theory, while sharp concepts lead to sharp extensions, vague concepts such as (proto)type concepts lead to vague extensions. The paper presents this understanding of Husserl in detail and explains its philosophical significance.
\end{abstract}


Keywords: Husserl; Prototype Concepts; Vagueness; Extension

\section{Introduction}

In contemporary philosophy, the debate about concepts often focuses on their 'ontological status'. Are concepts mental representations, as Fodor (1987) holds? Are they rather abstract objects, that is, atemporal mind-independent entities, as neo-Fregeans such as Peacocke (1992) maintain? Or are they abilities to classify, as neo-Wittgensteinians such as Glock (2011) claim? In parallel to this discussion, however, contemporary philosophers are increasingly interested in the question of the 'structure of concepts'. Philosophers have traditionally taken concepts to have a 'definitional structure': a concept contains a fixed number of marks, which represent the 'singly necessary and jointly sufficient' properties that must be instantiated in order for something to fall within the extension of the concept (Margolis and Laurence 1999, 9 n. 8). More recently, an alternative account has been developed, initially by cognitive scientists and then also by philosophers, namely, the 'prototype theory of concepts' (Rosch and Mervis 1975; Hampton 2006; Prinz 2012; Del Pinal 2016). According to this view, a concept is not a definition; rather, it represents properties the instantiation of some of which is enough for something to fall within the extension of the concept. The member that instantiates all the properties is the 'prototype', and things within the extension have a greater or lesser similarity to this typical case (the foregoing summarizes, and quotes from, material found both in Margolis and Laurence 1999 and 2019). Prototype concepts are vague, that is to say, at a certain distance from the typical member the resemblance to the prototype is such that one can neither affirm nor deny that something falls under the concept (see, e.g., Hampton 2007). 
This alternative account of concepts is often said to originate in Wittgenstein's theory of 'family resemblances' (1953; see again Rosch and Mervis 1975, as well as Margolis and Laurence 2019). According to Wittgenstein, our concepts gather together items that are more or less similar, and they have 'blurred edges'. But do family resemblances entail that there is some family member that is the prototype? It is not so clear that they do. Some interpreters point to texts in which Wittgenstein talks of more or less exemplary cases for some families (see Baker and Hacker 2005, 213 and Glock 1995, 120-124, basing themselves on Wittgenstein 1970,190), but this does not say whether it is intrinsic to the notion of family resemblances that it comes with typicality.

Before Wittgenstein, however, there was a philosopher who clearly anticipated and developed in detail the prototype theory, namely, Husserl. Indeed, the late Husserl accepts what he calls 'type concepts' (Typenbegriffe) (for the expression, see, e.g., 2012, Hua XLI, 251.16). In addition to being organized around a 'type', these concepts, according to Husserl, have an extension made up of objects that have a greater or lesser similarity to the typical case, and they are vague. Unfortunately, the fact that Husserl anticipated and developed the prototype theory, which is noteworthy from a historical point of view, has gone unnoticed by his readers, who, as I would like to show, wrongly treat type presentations as pre-conceptual cognitive tools. ${ }^{1}$

Besides the historical significance of his theory, Husserl also makes a philosophically interesting contribution in affirming that it is not only type concepts themselves that are vague, but also their 'extension' (Umfang) (2012, Hua XLI, 284.13). Thus, whereas in the prototype theory vagueness is a property of the concept (see, e.g., Hampton 2007), Husserl holds explicitly that the 'extension' of a type concept is itself vague. Now, an extension is

\footnotetext{
${ }^{1}$ On the relation of Husserl and Wittgenstein on this point, see Bégout 2002, who nonetheless does not connect the discussion to the prototype theory.
} 
usually treated as simply a set of items, and thus something firmly delimited, or sharp. However, I would like to argue that Husserl develops an original, correlationalist theory of concepts in general, and of type concepts in particular, such that for the specific characteristics in the structure of the concept there are corresponding characteristics in the arrangement of its members (both clear and doubtful), and vice versa. More precisely, because of its structure, a type concept contains within its extension typical members, members of greater or lesser similarity to the typical case, and borderline cases, these last accounting for the concept's vagueness. The correlation in question, however, is based on a one-way dependency: if the arrangement of (clear and doubtful) members of type concepts is organized in such a way, this is because of specific features in the structure of the concept.

In the first section of the paper, I will briefly present Husserl's theory of type concepts by explaining his account of their ontological status and how they are acquired, and why they are genuine concepts. I will then turn to the question of the so-called 'extension' and structure of type concepts, and examine Husserl's correlationist view in detail. I will conclude by discussing the originality of Husserl's idea that the structure and 'extension' of concepts should be thought of in correlation with each other.

\section{Husserl on the Ontological Status and the Acquisition of Type Concepts}

In his Logical Investigations, the early Husserl defends the definitional theory of concepts, combined with an abstract account of their ontological status. Concepts are addressed in the context of the discussion of 'ideal' meanings, in the sense of Plato's abstract 'Ideas'. Ideal meanings are atemporal, mind-independent entities (1984, LU I, Hua XIX/1, 104.21-106.32, and II, Huа XIX/1, 128.30-131.13). They are divided into concepts and propositions. Whereas propositions are the meanings of sentences, concepts are the meanings of common names (1984, LU VI, Hua XIX/2, 617.34-618.1). The early Husserl explicitly denies that there could 
be 'vague meanings'; if there is something like vagueness in our linguistic expressions, this can only be due to our 'fluctuating' use of words, since we use the same name for a series of more or less similar meanings. Husserl even holds that among those meanings, some might be more 'typical' than others; that is, they might be more likely than others to be what is meant by the name. However, this does not entail that the concepts expressed by the name have a vague structure or are organized around a typical member. The meanings themselves are sharp, and none of them is intrinsically either more or less typical than any other $(1984, L U \mathrm{I}$, Hua XIX/1, 94.7-97.6; on typicality in early Husserl, see Benoist 2010, and for a longer and more detailed discussion than here, see Taieb 2021).

Concepts and propositions are not unrelated to our cognitive activities: when we have conceptual representations and judgements, the contents of our mental acts are instances of ideal concepts and propositions (1984, LU I, Hua XIX/1, 104.21-106.32). However, ideal concepts and propositions exist independently of their being instantiated as parts of mental acts (1984, LU I, Hua XIX/1, 110.5-15). The exact status of these ideal objects and of their mode of being, however, remains rather underdetermined in the Logical Investigations, and Husserl later struggled in trying to explain in exactly what sense one can speak of mental concepts and propositions as instances of mind-independent objects (see notably Husserl 1987, Huа XXVI, 202.8-219.33). ${ }^{2}$

It is perhaps in view of these difficulties that the later Husserl both modifies and enriches his account of concepts (and propositions). First, he defends the idea that they are 'mental products' (psychische Gebilde) and thus 'unreal', in the sense of 'non-spatial':

\footnotetext{
${ }^{2}$ For Husserl's evolution on this difficult question, see Künne 2013. I will not discuss this point here, as it would require a lengthy treatment; on this issue, see Taieb 2018.
} 
To be sure, the thoughts do not make their appearance in consciousness as something 'external'. They are not real objects, not spatial objects, but unreal products produced by the mind; and their peculiar essence excludes spatial extension, original locality, and mobility. ${ }^{3}$

He still speaks of concepts (and propositions) as having some 'ideality' (Idealität), but by this he means simply that various thinkers can produce, and thus think, the same conceptual (or propositional) content (1939, 303-317; cf. 2008, Hua XXXIX, 298.8-300.21). ${ }^{4}$ Among concepts, or conceptual presentations, Husserl distinguishes various kinds. First, he accepts 'pure' concepts, which are independent of experience and are formed on the basis of an 'intuition of essences' (Wesensschau); this intuition presupposes the intuition of an individual, but one which can be a mere product of imagination. Second, he accepts empirical scientific concepts, which depend on experience: they are the result of an abstraction based on scientific, 'systematic and methodical experience' (2012, Hua XLI, 250.20). Finally, he explicitly introduces 'type concepts' (Typenbegriffe) (see, e.g., 2012, Hua XLI, 251.16), which are based on ordinary experience and are thus not derived from scientific investigation (Husserl 1939, 398-403; cf. 2012, Hua XLI, 244.7-251.26). In short, the later Husserl is a 'pluralist' about concepts (Weiskopf 2009; Margolis and Laurence 2019; for a recent analysis of Husserl's pluralism with respect to pure and empirical concepts, see Wolf 2020). Although the exploration of each of these kinds of concepts for itself, and of their interaction, would be

\footnotetext{
${ }^{3}$ Husserl 1974, Hua XVII, 163.3-7; trans. Cairns, slightly modified; see also Husserl 1976, Hua VI, 132.32-133.9.

${ }^{4}$ For a similar position in contemporary philosophy, see Placek 1996 and Moltmann 2013. On Husserl's theory of mental products, see again Taieb 2018.
} 
an interesting task, I will not discuss this further in this paper, but will focus on type concepts. $^{5}$

According to Husserl, type concepts are built passively, via association of ideas: we encounter things in our environment which bring to mind more or less similar things that we have already encountered. As he puts it: 'What is given in experience as a new individual is first known in terms of what has been genuinely perceived; it calls to mind the same (the similar)' (Husserl 1939, 399; trans. Churchill and Ameriks; cf. 2012, Hua XLI, 249.4-6). The thing seen now and (the representation of) the thing seen previously partly 'overlap' (Deckung) and are 'synthesized'. Husserl develops a phenomenological account of similarity, based on our experience of congruence between things in our environment. He describes similarity as a partial overlapping of two or more numerically distinct things (or their representations), in contrast to sameness, which is a perfect overlapping of numerically distinct items (or their representations) $(1939,223-227$ and 385-388; on the fact that one of the correlates of the overlapping is sometimes an object in memory, see Husserl 2008, Hua XXXIX, 388.12-16). The overlapping itself, which is described as a sort of 'synthesis', seems to refer to a primitive experience (on all these questions, see more broadly Husserl 1996, Hua XI). ${ }^{6}$ The aspects under which things overlap form a 'type'. For example, when I see a dog, it reminds me of dogs that I have already seen; this dog and (the representations of) previously seen dogs partly overlap, and the aspects under which these animals overlap form the type

\footnotetext{
${ }^{5}$ On Husserl's adoption of type concepts, see Bégout 2002 and Lohmar 1998; for a general presentation of Husserl's account of concepts, see Beyer 2011.

${ }^{6}$ I am grateful to Mark Textor for the idea that this is to be described in terms of a primitive experience.
} 
'dog'. This happens passively, without me deliberately bringing these things together and abstracting a type (on the type 'dog', see 1939, 399-401; cf. 2012, Hua XLI, 249.3-250.8). ${ }^{7}$

Note that for Husserl, sameness as present in our experience has its own rules, which differ from the logical rules to which it is normally subject. The 'law of third-sameness' (der Satz von der Dritten-Gleichheit) holds 'approximately' (ungefähr), and that of 'n-sameness' (n-te Gleichheit) does not hold; in other words, it might happen that $\mathrm{a}=\mathrm{b}$ and that $\mathrm{b}=\mathrm{c}$ but that $\mathrm{a} \neq \mathrm{c}$ (2012, Hua XLI, 232.32-233.12 and 258.12-30; see also 228.27-229.10). The example that Husserl gives is of someone who wants to buy a scarf of the same colour as a dress that he or she owns; he or she finds a piece of fabric at home which is of the same colour as the dress, takes it out, uses it as a sample to buy the scarf, but once at home, he or she sees that the dress and the scarf are not of the same colour. In his or her experience, however, the dress and the piece of fabric are perfectly overlapping (are the same) with respect to their colour, and this also holds for the piece of fabric and the scarf (2012, Hua $\mathrm{XLI}, 230.7-13$ ). What justifies that $\mathrm{a}=\mathrm{b}$ and that $\mathrm{b}=\mathrm{c}$ is the overlapping given in the experience: ${ }^{8}$ the colours are the same, or, as Husserl adds, their difference is 'unnoticeable' (2012, Hua XLI, 258.20-21). However, it is also given in the experience that a $\neq \mathrm{c}$, hence the special character of the rules of experiential sameness. This anticipates what contemporary authors call the 'non-transitivity of indiscernibility'; what it reveals is that we are unable to

\footnotetext{
${ }^{7}$ Although the initial comparison which leads to the abstraction of the type 'dog' is made between particulars, the type itself is a general content. If it were not, then Husserl's view would resemble more the 'exemplar theory of concepts' (Brooks 1987), according to which our concepts are deprived of any general content, but are organized around the representation of an individual, which members in the extension resemble to a greater or lesser degree. I am grateful to an anonymous referee for emphasizing this point. For more on the contents of type concepts, see below.

${ }^{8}$ I am grateful to Mark Textor for this idea.
} 
clearly distinguish slight differences in our environment and are thus prone to classifying one and the same thing under different categories on different occasions, which leads to the vagueness of these categories (see Egré 2018, 59-61).

Type concepts represent various kinds of features. First, they represent sensory qualities such as shape and colour; for example, the shape and colour of the teeth of a dog. Second, they show developmental and causal features; for example, the way a dog eats and runs (1939, 399 and 403; 2012, Hua XLI, 249.8-15 and 250.27-31). Type concepts are expressed by 'natural' (natürlich), or 'common' (allgemein) language, that is, ordinary language (Husserl 2012, Hua XLI, 276.15 and 315.21-23). Husserl says sometimes that what these concepts are about are 'type essences' (typische Wesen); according to him, these essences themselves are 'fluctuating' (fließend) (2012, Hua XLI, 67.14-18). It is not clear whether Husserl is ontologically positing the essences in question, or whether they are a mere façon de parler which somehow reifies what the concept represents. Usually, Husserl is a realist about essences, and speaks of them as something that we can grasp thanks to a special kind of intuition which he calls the 'intuition of essences' (Wesensschau) (Husserl 2012, Hua XLI); however, he holds that type essences are the result of an 'abstraction' in which something is 'raised into the region of essences', which seems rather to be a commitment to non-realism (see 1977, Нua III/1, 155.32-39; trans. Kersten). If type essences really existed by themselves, and if 'fluctuating' meant 'vague', this would be an innovative case of ontic vagueness: the vagueness of essences.

Though Husserl describes type presentations as 'general' (see, e.g., 1939, 399; cf. 2012, Ниа XLI, 249.24-25), it has often been argued that these representations are not conceptual. It is true that Husserl does not call his type presentations 'concepts' in the book which scholars usually quote when discussing his account, namely, Experience and Judgement, mostly pp. 398-403, a book edited by Husserl's assistant Ludwig Landgrebe 
(Husserl 1939). Also, Husserl apparently never says in this book that these cognitive tools are expressed in language; and one might think that this is another clue that they are not conceptual, at least if one draws a close connection between language mastery and conceptual abilities. This has led his readers to say that type presentations are pre-conceptual cognitive means, more precisely, that they are non-intellectual habits that are independent of language (see Lohmar 1998, 2008 and 2014, as well as van Mazijk 2020, 115-117 and 136-137; for the rejection of type presentations as concepts, see also Wolf 2020,4). They have even been explicitly contrasted with concepts expressed in ordinary language (see Lohmar 2014, 53-54).

When one looks in other texts of Husserl, however, things are quite different. First, in the manuscripts edited in the Husserliana volume on essences, the expression 'type concepts' (Typenbegriffe) appears quite often (see Husserl 2012, Hua XLI, 71.32, 73.22, 75.32, 117.31, 230.1, 233.13, 233.27, 234.19, and 251.16). Interestingly, it even appears in the manuscript which Landgrebe used as a source for Experience and Judgement, pp. 398-403 (which is reproduced in the Husserliana volume in question), but he did not include the paragraph where the expression occurs (see 2012, Hua XLI, 251.16). ${ }^{9}$ Moreover, in the same Husserliana volume, Husserl holds, as noted above, that type concepts are expressed in ordinary language (see 2012, Hua XLI, 276.15 and 315.21-23). So it seems reasonable to argue that type presentations in Husserl are concepts, although of a specific kind.

Another argument in favour of a conceptualist reading can be drawn from the scientific context in which Husserl developed his views. Scholars usually struggle with the

\footnotetext{
${ }^{9}$ In this paper I frequently cite Husserl 1939. Note, however, that the original manuscripts of the passages on which I mostly rely have been published either in Husserl 2012, Hua XLI or in Husserl 2008, Hua XXXIX, making it possible for me to check whether I am quoting Husserl himself. On the composition of the 1939 volume and its relation to Husserl's Nachlass, see Lohmar 1996; a new edition of this volume is currently in preparation at the Husserl Archives in Cologne.
} 
source of Husserl's theory of type presentations, and some have argued that Kant's account of sensory synthesis (or 'schemata') might be a predecessor (Lohmar 2003). This would again make these cognitive means non-conceptual items. But in fact, Husserl's source seems different. The notion of type concept was quite common at the time of Husserl. It is developed by a colleague of his in Halle, Benno Erdmann (1894), who wrote on the theme in a journal issue in which Husserl himself published a text ('Psychologie Studien zur elementaren Logik. I'), so Husserl might have discovered Erdmann's paper by serendipity, if not during a discussion between colleagues. At any rate, Husserl quotes it in the Logical Investigations (where, however, he does not yet accept type concepts) (see 1984, LU I, Hua XIX/1, 94 n. 1 and Taieb 2021). In addition, and more importantly, the notion of type concepts was present in the School of Brentano, in which Husserl started his philosophical development. The clearest account of type concepts is found in Anton Marty’s Untersuchungen, a book that Husserl reviewed (see 1979, Hua XXII, 261-265). In this book, Marty accepts what he calls 'concepts built following types' (nach Typen gebildete Begriffe), which, as he explicitly says, gather together more or less similar things and are 'vague' (verschwommen). Interestingly, Marty already accepts concept pluralism, since he says that while our ordinary concepts are built around types, most of our scientific concepts are definitional (1908, 527-531) (on Marty on these issues, see Mulligan 1990 and Taieb 2020). One also finds in Meinong a specific kind of abstract presentations organized around a typical case or 'type' (Type), as he explicitly says, and which gather together more or less similar items $(1968,480-492)$. Thus, although Husserl's account of type concepts is very well developed, and certainly more than those of Marty and Meinong - which gives it a specific importance - it did not come ex nihilo, nor did it come from Kant, but was inspired by theories of concepts that were circulating among his contemporaries. 
In the final analysis, however, note that even if Husserl himself would have been reluctant to use the word 'concept' for his type presentations, since he had argued that general representations acquired passively and via association of ideas are not 'concepts', this would reveal a merely linguistic issue. For many scholars working in contemporary philosophy would call such representations 'concepts' (on the polysemy of the word 'concept', see Machery 2009).

\section{From the Structure to the Domain of Type Concepts}

Husserl's theory of type concepts is akin to the prototype theory. As pointed out in the introduction to this paper, according to the prototype theory concepts are not definitions: rather, they represent properties the instantiation of some of which is enough for something to fall within the extension of the concept. The bearer of all the properties is the 'prototype'; membership is fixed by relations of similarity to this representative item, and the concept gathers under it objects that are more or less similar to the typical case (see Margolis and Laurence 1999, especially 27-28, and 2019). Though the prototype is sometimes described in the literature as an existing species of the genus that the concept is the concept of, such as sparrows for birds, it is best understood as the content of the concept of this species, that is, the intension of this specific concept (Margolis and Laurence 1999, 25 n. 30 and 28 n. 35). More simply, the prototype can be described as the series of properties represented by the prototype concept; the prototype of birds would thus be: 'fly, sing, nest in trees, lay eggs' etc. (see Margolis and Laurence 1999, 27-28). ${ }^{10}$ Hampton presents the understanding of a prototype concept as the representation of a series of properties as follows:

\footnotetext{
${ }^{10}$ Note that this account might have some theoretical advantages over the view that the prototype is an existing species; for one, it would explain how prototype concepts can combine, thus answering the
} 
A prototype represents a kind in terms of its most common and typical properties. However, no individual property need be true of the whole kind (although some may be), so that belonging to the category simply involves possession of a sufficient number of such properties. Exemplars will also differ in typicality as a function of the number of such properties they possess. More broadly, a prototype concept is one whose reference is the set of all exemplars whose similarity to a prototype representation is greater than some threshold criterion. $^{11}$

Importantly, prototype concepts are vague, that is, things falling under the concept may gradually draw away from the typical case to the point that they become 'borderline cases' (Hampton 2007). ${ }^{12}$

Husserl's notion of 'type concepts' (Typenbegriffe) at first glance seems to be close to this theory, in both substance and terminology. However, a first question to ask is whether there is anything like typicality in his account, since a 'type' might be simply a 'kind', in contrast to a 'token', and nothing like a representative member. Some hints of an answer might be found in the following passage:

objection that these concepts do not allow for compositionality. For a presentation of the problem of compositionality, see Margolis and Laurence 2019.

${ }^{11}$ Hampton 2016, 129.

${ }^{12}$ It must be emphasized that vagueness does not pertain exclusively to prototype concepts as contrasted with definitional concepts. Although definitional structure entails that there is a determinate number of necessary and sufficient properties that must be instantiated for something to fall under the concept, this does not mean that the concept is sharp: a definition can include some vague marks, and so a concept with definitional structure can also be vague (on this, see Margolis and Laurence 1999, 24). 
I am, for example, arriving in an unfamiliar environment. The individual typology (Typik) is imperfectly known to me: a plant, but an unfamiliar one, a field, but covered with field plants distinct from 〈those $\rangle$ I am acquainted with (vertraut). The way of working the field: I do not know what is typical (das Typische) in the cultivation of such fields. A house, but of an unfamiliar character. Is it a temple? Is it a public building? - I am in China. In the market, trade and change, but in an unfamiliar typology. I know that it has a typology, but I don't know it; but the people there in the market do. ${ }^{13}$

This passage does indeed seem to refer to something like 'typicality', or representative members: one's type concept of 'flower' is such that one can subsume flowers under it although one is 'unfamiliar' with them - that is, although they are not typical, in contrast to those one is 'acquainted with' - and one is able to recognize something as a case of cultivation although one does not know what the typical mode of cultivation is in the new context, in contrast to the case one is familiar with. ${ }^{14}$ 'What is typical' (das Typische) among the members of a concept seems to be an existing species, for example, specific flowers, such as daisies, specific modes of cultivation, etc.; and they might be typical for me or for someone else, for example, people in China. In another passage (2008, Hua XXXIX, 447.31-448.2), Husserl makes a further distinction: he speaks of a 'specific type' (Sondertypus) which is the 'long-known' (altbekannt) item in a given category; this 'long-known specific type' seems to refer to the familiar or typical member of the class, for example, daisies for flowers.

\footnotetext{
${ }^{13}$ Husserl 2008, Hua XXXIX, 159.17-25; see also 2008, Hua XXXIX, 429.31-430.11.

${ }^{14}$ For Husserl, the notions of typicality and familiarity apparently overlap, though one might claim that they are distinct. Prima facie at least, something can be both atypical and familiar, e.g. when someone has an atypical dog as a pet. I am grateful to an anonymous referee for this idea.
} 
Presumably, when Husserl speaks of 'types' in terms of an overlapping of properties of things in our environment, he is referring to the typical item of the category, that is, the 'long-known specific type'. Though he sometimes speaks as if the type (i.e., the typical case) were an existing species, for example, daisies, I take him to mean rather that the type is a conceptual content or intension. He even says sometimes that type concepts are 'general presentations' with 'typical marks' (typische Merkmale); this suggests that he might think that a 'long-known specific type', or more simply a 'type', is just the series of properties represented by the type concept (see 1939, 399-400; cf. 2012, Hua XLI, 249.24-36). To be sure, Husserl's terminology is a bit misleading, since he often uses 'type' for the type concept, not for the typical case (e.g., in Husserl 2012, Hua XLI, 388.23-27, quoted below). But in general, his idea is that our type concepts are organized around a typical case, and that what falls under the concept goes beyond this typical case. This is similar to the contemporary view on prototype concepts.

Another question is whether in Husserl the things falling under a type concept form a network of relations of similarity, as in the contemporary view on prototypes. It seems that this is the case. Husserl often speaks of type concepts as having 'horizons of similarities' and holds that things 'in the type' (im Typus sich haltend), that is, within the extension of the type concept, can be 'merely similar':

The world is already pre-given in such a way that every reality is apperceived in a typical way, and thus has a horizon of possibility of similar things, of typically the same things. [...] $\langle$ Something $\rangle$ seen as the same can, in the relativity of the way of givenness of proximity and distance (in general: of perfection), by closer observation, in which it is better seen, what it is, appear as different - but simply similar, i.e. still being in the type. ${ }^{15}$

\footnotetext{
${ }^{15}$ Husserl 2012, Hua XLI, 388.8-10 and 23-27.
} 
Finally, Husserl explicitly affirms that type presentations are 'vague'. He means to attribute vagueness not just to type concepts, but also to their 'extension' (Umfang) (see 2012, Hua XLI, 66.8-12 for the attribution of vagueness to concepts, and 284.13 for the attribution to their extension). ${ }^{16}$ His idea seems to be that there is something specific in the structure of type concepts which makes their extension vague. But before trying to clarify what exactly this specific feature might be, it it necessary first to see how the very idea of a vague extension could make sense.

In contemporary philosophy, extensions are usually understood in terms of sets. As described by Sainsbury (2012, 252 and 253), 'a predicate, linguistic vehicle of a concept, is thought of as having a meaning which fixes its extension, the set of things of which it is true'. Sets have 'boundaries', and concepts are 'boundary drawers'. By contrast, 'vague predicates and vague concepts do not have "extensions" - sets of things of which they are true', and so they are not boundary drawers. Thus, if a predicate and its corresponding concept are vague, it is not possible to speak of them as having an 'extension'. ${ }^{17}$ Now, Husserl explicitly attributes

\footnotetext{
${ }^{16}$ As noted above, Husserl also talks of type essences, and describes them as 'fluctuating' (2012, Hua XLI, 67.14-18), which might mean that they are vague too (if it is admitted that they truly exist).

${ }^{17}$ Note, however, that there are exceptions to this. First, even if Hampton (2007) says that what is vague is the prototype concept and not the extension, he still thinks that there is a correlation between the intension and extension of such concepts - or more precisely, between the weight for membership fixation of the properties represented by the prototype and the degree of typicality possessed by individuals which instantiate these properties. (I thank James Hampton for drawing my attention to this point.) Moreover, in a dialetheic framework, in which borderline cases are treated as 'glutty' items to which a vague predicate applies both truly and falsely, it might be correct to talk of an 'extension' with vague frontiers, in the sense that the extension includes both the items to which the predicate
} 
vagueness to the 'extension' itself of type concepts: 'the extension 〈is〉 vague' (2012, Hua XLI, 284.13). More precisely, he states that type concepts have a 'logically undetermined extension' (logisch unbestimmter Umfang) in the sense that it is always possible to encounter individuals whose 'subsumption' is 'doubtful' (fraglich) (2012, Hua XLI, 67.14-18 and 233.25-37). This seems to hold for all type concepts, since it is intrinsic to them that membership is fixed by greater or lesser similarity to a typical case. Williamson's $(1994,86)$ comment about Wittgenstein could also be made about Husserl: 'Family resemblance concepts are obviously susceptible to borderline cases. How much resemblance to previous cases is sufficient for something to be a game?'

But again, although it is usual to hold that a concept is vague (see, e.g., Hampton 2007), can an extension be vague? As seen above, Husserl says that it can. One way to make sense of this would be to hold that for Husserl, whereas concepts are vague when they allow for borderline cases, extensions are vague when they include borderline cases. Apparently, what Husserl calls an 'extension' is constituted by both the members of the concept and the way they are arranged. Moreover, Husserl thinks that the arrangement between the members is correlative to the structure of the concept: if the concept's structure is such that it allows for typicality, a greater or lesser degree of similarity to a typical case, and vagueness, then these features must be found in the arrangement among the (clear and doubtful) members of the

applies merely truly and those to which it applies also truly (on dialetheism and vagueness, see Priest, Berto, and Weber 2018). In addition, there have been explicit objections to the thesis that a set is necessarily sharp, namely, in fuzzy set theories, first elaborated by Zadeh (1965) and further developed into a theory of vague sets by Gau and Buehrer (1993). However, the notion of 'vague set' has been received with some scepticism in philosophy (see Horgan 1990, 554 n. 16). Although Husserl himself did not fully elaborate a fuzzy logic, his notion of vague extension clearly anticipates this tradition. 
concept. The extension is fixed 'from inside' the concept, so to speak, and on the basis of the concept's structure.

Since the concept gathers together more or less typical things, there are more or less typical things within the extension (in relation to the concept under which they fall); for example, it is a feature of sparrows to be more typical birds than penguins; that is, sparrows have more of the typical properties of the concept of bird (in fact, they have all of them) than penguins do. Since the concept gathers together things that are more or less similar to a type, there are things that are more or less similar to the type within the extension (in relation, again, to the concept under which they fall); for example, it is a feature of penguins to be less similar to the typical birds, that is, to sparrows, than pigeons are. Note that although the overall relations of resemblance and lack of resemblance between items within the extension are not imposed on them by the concept, the properties which are used to estimate the degree of similarity or dissimilarity depend on the concept: penguins are less similar to sparrows than pigeons are from the point of view of the properties under which sparrows are represented in the concept, namely, 'flying', 'singing', 'nesting in trees', and 'laying eggs' (for the list, see again Margolis and Laurence 1999, 27-28). If you were to take the internal physiological organization of sparrows, penguins might be more similar to sparrows than pigeons are (though I am not an ornithologist); and with respect to the constitution of their atoms, they are all equally similar. Thus, penguins are less similar to sparrows than pigeons are in relation to the prototype concept of bird. Finally, since the concept is vague, there are things within the extension of which it is not clear whether or not they fall under the concept, that is, borderline cases; this again is a feature of these things themselves (in relation to the concept under which it is not clear whether they fall or not). In this sense, what Husserl calls the 'extension' of the concept is vague. In short, the structure of the concept is reflected in the arrangement among the (clear and doubtful) members of the concept: there is an ordering among them, from 
typical cases to borderline ones, according to a decreasing degree of similarity to the typical case.

Husserl indeed uses the word 'extension' (Umfang) to refer to the members' vague arrangement. This might be terminologically undesirable, as one might like to reserve the word 'extension' for sets, and thus for firmly delimited entities, as is usually the case (Sainsbury 2012). ${ }^{18}$ An alternative would perhaps be to speak of the 'domain' of a concept. At any rate, what is certain is that for Husserl, concepts and the arrangements among their members should be thought of in correlation. Note that there is a symmetric, isomorphic relation as regards the structure of the concept and the nature of the so-called 'extension', hence a 'correlation', whereas the explanatory relation between them is asymmetric: it is because the concept has the structure it has that there is this specific arrangement among the members.

Let us now come to the analysis of the structure of type concepts. Husserl's point seems to be that the nature of the arrangement among the members of a concept depends on the structure of the concept in question. So what exactly in the structure of a type concept is responsible for the 'extension' or 'domain' being made up of typical items, of things of greater or lesser similarity to them, and of non-sharp boundaries? One option would be to hold that the concept has as its content not just the type, but a plurality of more or less typical entities. For example, the concept of 'bird' would have as its content not only 'sparrow', but also 'penguin', etc., with some of these items being more typical than others (on the idea that a concept is made up of a plurality of contents, which can alternately play the role of the prototype in various contexts, see Prinz 2012 and Del Pinal 2016). This view might help to explain why the domain of a concept contains both typical members and things of greater or

\footnotetext{
${ }^{18}$ See again, however, the exceptions mentioned in the previous footnote.
} 
lesser similarity to them. But would this be enough to account for vagueness? It seems not: each of these contents would as such be firmly delimited and thus would have a definite extension corresponding to it, but the multiplication of sharp contents does not lead to vagueness (on this, see Sainsbury 2012).

An alternative view would be to hold that a type concept is a complex entity made up of a representation of a type combined with an ability for classification that is indeterminate and thus explains why the concept is vague. More precisely, beyond the representation of the type, every type concept would come with an ability to judge that ' $x$ is $C$ ', which would depend on a computation of the degree of similarity that $x$ has to the type of $\mathrm{C}$, but combined with an ignorance about the exact level of similarity required in order to classify things under the concept; this ignorance would explain the concept's vagueness (for such a 'similarity comparison process', see Barsalou 1987, 116, as well as Margolis and Laurence 2019; for an analogous explanation of concept vagueness, see Hampton 2007, 379). Note that here, interestingly, the adequate account of the 'structure' of the concept appeals to a specific understanding of its 'ontological status', namely as a combination of a representation and an ability. ${ }^{19}$

Can such a view be applied to Husserl? At first sight, it seems that it would be illegitimate to do so, since Husserl consistently holds that type concepts are built and used 'pre-predicatively', that is, before any judicative operation (see Husserl 1939 and 2012, Hua XLI). However, when he speaks of general 'judgements', he has in mind a specific sort of mental act - namely, one in which there is a 'thematic' consciousness of generality, that is,

\footnotetext{
${ }^{19}$ One might be sceptical about the use of the word 'concept' to refer to such a complex entity, which includes a computation process, that is, something usually not counted among concepts. An answer to this objection would simply be to admit that the word 'concept' is not a natural kind name, but is used for entities that have various natures (this position is defended by Machery 2009).
} 
where one attends to the type and then subsumes an individual under the type concept. He also accepts other kinds of, say, 'determinations' (Bestimmungen), which he describes as the passive grasping of something as belonging to a type concept. ${ }^{20}$ Does Husserl somewhere speak of an ability like the one described above? It might be that he does, or at least hints at it, in the following (rather intricate) text:

The type is a general presumption about similar explained items to be found or about a general explanation in terms of typical explained items; a general pre-opinion with a general sense, which possibly fulfils itself through individualized and determined true explanation. ${ }^{21}$

The claim that a type, or a type concept, includes a 'general pre-opinion' (allgemeine Vormeinung) that similar things are to be found which could be 'explained' in the same way might refer to an ability to classify things under the concept via a comparison of similarity. To be sure, what Husserl calls an 'explanation' is something active, namely, the classification of an individual under a type concept via a thematic consciousness of generality, but he explicitly holds that the pre-opinion in question is prior to any explanation (see 2012, Hua XLI, 106.32-33). Moreover, although the text says that the type presentation 'is' a pre-

\footnotetext{
${ }^{20}$ See 2012, Hua XLI, 111.33-36, and 273.11-35 (but which Husserl describes as unsatisfying in a note), as well as 1939, 398-403 (2012, Hua XLI, 248.35-250.31). The fact that Husserl treats type concepts as 'pre-predicative' has also led interpreters to hold that they are non-linguistic (see, e.g., Lohmar 2008, 153). But I must confess that I have some difficulties in seeing why: something prepredicative is pre-judicative, but not necessarily pre-linguistic. At any rate, as noted above, Husserl (2012, Hua XLI, 276.15 and 315.21-23) is happy to say that type concepts are expressed in ordinary language.

${ }^{21}$ Husserl 2012, Hua XLI, 107.1-4.
} 
opinion, I do not take this to mean that it is nothing other than such a pre-opinion, since, as noted above, Husserl describes type concepts as 'general presentations' which have 'typical marks'; that is, type concepts do indeed seem to be constituted by a representation of typical properties (see 1939, 399-400; cf. 2012, Hua XLI, 249.24-36). Thus, according to this interpretation, Husserl's type concepts are a combination of the representation of a type and an undetermined ability to classify; this ability computes the degree of similarity of items to the type, but the exact level needed for the classification to be legitimate is not known.

As for the origins of the ignorance in question, it would probably come, for Husserl, from our inability to notice small qualitative differences in our environment, a problem he points out explicitly, as noted above. This would make Husserl a defender of the epistemic theory of vagueness. However, such an account of the structure of type concepts would be compatible with the semantic theory of vagueness: the ignorance in question could be described as a 'semantic indeterminacy', in the sense that there would be no general agreement on the application of our concepts for specific cases, which would thus be labelled 'borderline'.22

\section{Conclusion}

The later Husserl is a 'pluralist' about concepts (Weiskopf 2009; Margolis and Laurence 2019) inasmuch as he distinguishes among pure concepts, empirical scientific concepts, and what he calls 'type concepts' (Typenbegriffe). This last kind of concept clearly anticipates contemporary prototype theory: Husserl's type concepts are organized around a typical case, things in the extension are more or less similar to this standard member, and these concepts

\footnotetext{
${ }^{22}$ For the application of semantic indeterminacy to the vagueness of concepts, see Hampton 2007, 379 ; on the distinction between the semantic and epistemic accounts of vagueness more broadly, see Egré 2018.
} 
are 'vague'. This is important from a historical point of view: Wittgenstein is usually mentioned as the predecessor of the prototype theory, but Husserl seems to be a much better precedent. Even if type concepts are found among other philosophers contemporary to him, including Brentanians, Husserl has a very developed view, and this makes his account noteworthy.

In addition, it is worth emphasizing that Husserl, in the context of his discussion of type presentations, develops a highly original correlationalist account of concepts. For Husserl, not only are type concepts themselves vague - that is, they allow for borderline cases - but also their extension is vague - that is, it includes borderline cases. What Husserl make us realize is that the arrangement among the members of a concept is sharp only when concepts themselves are sharp. Concepts are traditionally described as 'boundary drawers', that is, as arranging things into sets, which have sharp boundaries; however, Husserl shows us that this is not intrinsic to concepts, but depends on a specific kind of concept, namely, sharp concepts. When one changes the structure of a concept, and attributes vagueness to the concept, the arrangement among its members also becomes vague; after all, Husserl would say, being a borderline case is a property of a thing, notwithstanding the fact that this property is attributed to it in relation to a concept. In the case of type concepts, the arrangement among the members is such that they are ordered from the typical case to borderline cases according to a decreasing degree of similarity to the typical case.

Husserl speaks of the members of a concept and the way they are arranged, be it sharp or vague, in terms of extensions. His view seems to be that an extension is relative: it is always the extension of a concept. This allows him to say that a change in the structure of the concept implies a change in the nature of the extension. When concepts are vague, as is the case with prototype concepts, their extension is also vague. Now, one might be reluctant to speak of 'vague extensions', since the term 'extension' is usually understood as referring to a 
set, which is something sharp (Sainsbury 2012):23 perhaps 'domain' would be better. Thus, concepts would have (at least) two kinds of domains: sharp ones, that is, 'extensions', when the concepts are themselves sharp, and vague ones when they are vague. Independently of the terminological issue, however, what Husserl's theory of type concepts teaches us is that there is a correlation between the specificities in the structure of a concept and those in the arrangement among its members. The originality of this thesis has gone unnoticed.

\section{Acknowledgments}

A first draft of this paper was presented at an informal work-in-progress seminar organized by Nils Kürbis at King's College London in 2019. I am grateful to the participants for their remarks, especially Julien Dutant and Nils Kürbis. I also thank Gregor Bös for his written comments on an earlier draft of the paper. My special thanks go to Mark Textor, with whom I had lengthy discussions about various issues developed in the paper and who made very useful suggestions. Finally, I thank the anonymous referees and James Hampton for their helpful remarks on earlier drafts of the paper.

\footnotetext{
${ }^{23}$ However, see footnote 17 above for exceptions.
} 


\section{References}

Baker, G. P., Hacker, P. M. S. 2005, Wittgenstein: Understanding and Meaning. Part 1: Essays. Volume 1 of an Analytical Commentary on the Philosophical Investigations. $2^{\text {nd }}$ ed. Oxford: Blackwell.

Barsalou, L. W. 1987, 'The Instability of Graded Structure: Implications for the Nature of Concepts', in U. Neisser (ed.), Concepts and Conceptual Development: Ecological and Intellectual Factors in Categorization. Cambridge: CUP, 101-140.

Bégout, B. 2002, 'Un air de famille: La théorie husserlienne des types', Recherches husserliennes 17, 51-85.

Benoist, J. 2010, Concepts: Introduction à l'analyse. Paris: Cerf.

Beyer, C. 2012, 'Husserl über Begriffe', in V. Mayer, C. Erhard, M. Scherini and U. Meixner (eds.), Die Aktualität Husserls. Freiburg im Breisgau: Karl Alber, 88-113.

Brooks, L. R. 1987, 'Decentralized Control of Categorization: The Role of Prior Processing Episodes', in U. Neisser (ed.), Concepts and Conceptual Development: Ecological and Intellectual Factors in Categorization. Cambridge: CUP, 141-174.

Del Pinal, G. 2016, 'Prototypes as Compositional Components of Concepts', Synthese 193, 2899-2927. 
Egré, P. 2018, Qu'est-ce que le vague? Paris: Vrin.

Erdmann, B. 1894, 'Theorie der Typen-Einteilungen', Philosophische Monatshefte 30, 15-49 and $129-158$.

Fodor, J. 1987, Psychosemantics: The Problem of Meaning in the Philosophy of Mind. Cambridge, MA: MIT Press.

Gau, W.-L., Buehrer, D. J. 1993, 'Vague Sets', IEEE Transactions on Systems, Man, and Cybernetics 23, 610-614.

Glock, H.-J. 1996, A Wittgenstein Dictionary. Oxford: Blackwell.

—. 2011, 'A Cognitivist Approach to Concepts', Grazer Philosophische Studien 82, 131-163.

Hampton, J. A. 2006. 'Concepts as Prototypes', The Psychology of Learning and Motivation 46, 79-113.

—. 2007, 'Typicality, Graded Membership, and Vagueness', Cognitive Science 31, 355-384.

—. 2016, 'Categories, Prototypes and Exemplars', in N. Riemer (ed.), Routledge Handbook of Semantics. London: Routledge, 125-141.

Horgan, T. 1990, 'Psychologistic Semantics, Robust Vagueness, and the Philosophy of Language', in S. L. Tsohatzidis (ed.), Meanings and Prototypes: Studies in Linguistic Categorization. London: Routledge, 535-557. 
Husserl, E. 1939, Erfahrung und Urteil, ed. L. Landgrebe, Prague: Akademia (Trans. J.S. Churchill and K. Ameriks, London: Routledge, 1973).

—. 1966, Analysen zur passiven Synthesis (Hua XI), ed. M. Fleischer, The Hague: Nijhoff. —. 1974, Formale and transzendentale Logik (Hua XVII), ed. P. Janssen, The Hague: Nijhoff (Trans. P. Janssen, The Hague: Nijhoff, 1969.).

—. 1976, Die Krisis der europäischen Wissenschaften und die transzendentale

Phänomenologie (Hua VI), ed. W. Biemel, The Hague: Nijhoff.

—. 1977, Ideen zu einer reinen Phänomenologie und phänomenologischen Philosophie.

Erstes Buch (Hua III/1). Ed. K. Schuhmann. The Hague: Nijhoff. (Trans. F. Kersten, The Hague: Nijhoff, 1983.)

—. 1979, '[Besprechung von] A. Marty, Untersuchungen zur Grundlegung der allgemeinen Grammatik und Sprachphilosophie', in E. Husserl, Aufsätze und Rezensionen (1890-1910) (Hua XXII), ed. B. Rang, The Hague: Nijhoff, 261-265.

—. 1984, Logische Untersuchungen. Zweiter Teil (Hua XIX/1-2), ed. U. Panzer, The Hague: Nijhoff.

—. 1987, Vorlesungen über Bedeutungslehre: Sommersemester 1908 (Hua XXVI), ed. U. Panzer, The Hague: Nijhoff.

—. 2008, Die Lebenswelt (Hua XXXIX), ed. R. Sowa, New York: Springer.

—. 2012, Zur Lehre vom Wesen und zur Methode der eidetischen Variation (Hua XLI), ed. D. Fonfara, New York: Springer.

Künne, W. 2013, 'Intentionalität: Bolzano und Husserl', in S. Centrone (ed.), Versuche über Husserl. Hamburg: Meiner, 97-143. 
Lohmar, D. 1996, 'Zu der Entstehung und den Ausgangsmaterialien von Edmund Husserls Werk Erfahrung und Urteil', Husserl Studies 13, 31-71.

—. 1998, Erfahrung und kategoriales Denken: Hume, Kant und Husserl über vorprädikative Erfahrung und prädikative Erkenntnis. Dordrecht: Kluwer.

—. 2003, 'Husserl's Type and Kant's Schemata. Systematic Reasons for Their Correlation or Identity', in D. Welton (ed.), The New Husserl: A Critical Reader, Bloomington: Indiana University Press, 93-124.

—. 2008, 'Denken ohne Sprache?', in F. Mattens, Meaning and Language:

Phenomenological Perspectives. Dordrecht: Springer, 169-194.

—. 2014, 'Types and habits: Habits and their cognitive background in Hume and Husserl', Phenomenology and Mind 6, 40-51.

Machery, E. 2009, Doing without Concepts. Oxford: OUP.

Margolis, E., Laurence, S. 1999, 'Concepts and Cognitive Science', in E. Margolis and S. Laurence (eds.), Concepts: Core Readings. Cambridge, MA: MIT Press, 3-81.

-. (2019), 'Concepts', in E. N. Zalta (ed.), Stanford Encyclopedia of Philosophy (Summer 2019 Edition), https://plato.stanford.edu/archives/sum2019/entries/concepts/

Marty, A. 1908. Untersuchungen zur Grundlegung der allgemeinen Grammatik und Sprachphilosophie. Halle: Niemeyer.

Meinong, A. 1968, 'Abstrahieren und Vergleichen', in A. Meinong, Gesamtausgabe I, ed. R. Haller and R. Kindinger. Graz: Akademische Druck- u. Verlagsanstalt, p. 443-494. 
Moltmann, F. 2013, 'Theoretical Alternatives to Propositions. Propositions, Attitudinal Objects, and the Distinction Between Actions and Products', Canadian Journal of Philosophy 43, 679-701.

Mulligan, K. 1990, 'Marty’s Philosophical Grammar', in K. Mulligan (ed.), Mind, Meaning and Metaphysics: The Philosophy and Theory of Language of Anton Marty. Dordrecht: Kluwer, 11-27.

Peacocke, C. 1992, A Study of Concepts. Cambridge, MA: MIT Press.

Placek, T. 1996, 'Thought as a Product of Thinking', Conceptus 29, 191-203.

Priest, G., Berto, G. and, Weber, Z. 2018, 'Dialetheism', in E. N. Zalta (ed.), Stanford Encyclopedia of Philosophy (Fall 2018 Edition), https:/plato.stanford.edu/archives/fall2018/entries/dialetheism/.

Prinz, J. 2012, 'Regaining Composure: A Defence of Prototype Compositionality', in W. Hinzen, E. Machery, and M. Werning (eds.), The Oxford Handbook of Compositionality. Oxford: OUP, 437-453.

Rosch, E., Mervis, C. 1975, 'Family Resemblances: Studies in the Internal Structure of Categories', Cognitive Psychology 7, 573-605.

Sainsbury, R. M. 2012, 'Concepts without Boundaries', in R. Keefe and P. Smith (eds.), Vagueness: A Reader. Cambridge, MA: MIT Press, 251-264. 
Taieb, H. 2018, 'Building Objective Thoughts: Stumpf, Twardowski and the Late Husserl on Psychic Products', Archiv für Geschichte der Philosophie 100, 336-370.

—. 2020, 'Ordinary Language Semantics: The Contribution of Brentano and Marty', British Journal for the History of Philosophy 28, 777-796.

—. 2021, 'The Early Husserl on Typicality', in A. Dewalque, C. Gauvry, and S. Richard (eds.), Philosophy of Language in the Brentano School. Cham: Palgrave Macmillan, 263-278.

Weiskopf, D. 2009, ‘The Plurality of Concepts', Synthese 169, 145-173.

Williamson, T. 1994, Vagueness. London: Routledge.

Wittgenstein, L. 1953, Philosophical Investigations, ed. G. E. M. Anscombe, R. Rhees, transl. G. E. M. Anscombe. Oxford: Blackwell.

—. 1970, Das blaue Buch. Eine philosophische Betrachtung. Zettel, ed. R. Rhees, G. E. M. Anscombe, G. H. von Wright. Frankfurt am Main: Suhrkamp.

Wolf, W. C. 2020, 'Husserl on the Overlap of Pure and Empirical Concepts', European Journal of Philosophy, online first, 1-13.

Zadeh, L. A. 1965, 'Fuzzy Sets', Information and Control 8, 338-353. 